\title{
PRESENTACIÓN \\ Los archivos públicos en México: acceso, organización, transparencia y legislación
}

\author{
Daniela Spenser
}

U no de nuestros quehaceres es investigar en los archivos públicos y privados, nacionales, estatales y municipales, personales e institucionales, en México y fuera del país. A pesar de que en los últimos años la historia oral ha adquirido la categoría de una fuente fidedigna, los documentos escritos siguen siendo un recurso indispensable para la investigación de los historiadores y para que los expertos de otras disciplinas puedan historizar sus temas de estudio. Los archivos son nuestra herramienta fundamental y también de su organización y nivel de acceso depende la calidad de nuestra investigación. Es sabido que los archivos (públicos y privados) suelen contener apenas una fracción de la documentación generada por un individuo, una institución o un sector público. Precisamente, por tratarse de una fracción es obligación de los custodios de los archivos preservar con sumo cuidado y con base en los conocimientos archivísticos los documentos para poder conocer el pasado de cuya comprensión depende nuestra capacidad de construir el presente y el futuro.

En 2002 entró en vigor la Ley de Transparencia y Acceso a la Información Pública Gubernamental que incluyó la redefinición del acceso a los archivos públicos históricos. La ley desató una controversia entre los historiadores y sus promotores porque abarcó los archivos públicos históricos y, en consecuencia, subordinó el acceso y la transparencia a criterios políticos que caracterizan la ley. Sin que el objetivo de este número de Desacatos fuera discutirla, se invitó a especialistas, historiadores y archivistas a reflexionar sobre la relación entre la ley y la generación del conocimiento de la historia de acuerdo con la organización y el acceso a los archivos que la ley podría potenciar. El nivel de la organización de los archivos públicos, enmarcado en la normatividad para asegurar el acceso a éstos, es uno de los criterios para evaluar la calidad de la democracia del país.

En este número, Desacatos reúne cinco artículos que presentan diversas perspectivas sobre el estado en el cual se encuentran varios archivos: el Archivo General de la Nación, el Archivo Histórico del Instituto Nacional de Migración, el Archivo Histórico de Jalisco, el Archivo Histórico del Estado de Hidalgo y el Archivo Histórico del Centro Coordinador Tzeltal-Tzotzil en San Cristóbal de las Casas, Chiapas. Para ilustrar la idiosincrasia de los archivos añadimos dos testimonios: uno cuenta lo sucedido después de que en 1989 volaran sobre la ciudad de Saltillo los papeles firmados por Benito Juárez; el otro es un testimonio sobre la experiencia de búsqueda de materiales en los más variados archivos —nacionales y extranjeros- para poder construir la historia de los grupos

The Public Archives in Mexico: Access, Organization, Transparency and Legislation

DANIELA SPENSER: Centro de Investigaciones y Estudios Superiores en Antropología Social-Distrito Federal, México. spenser@prodigy.net.mx 


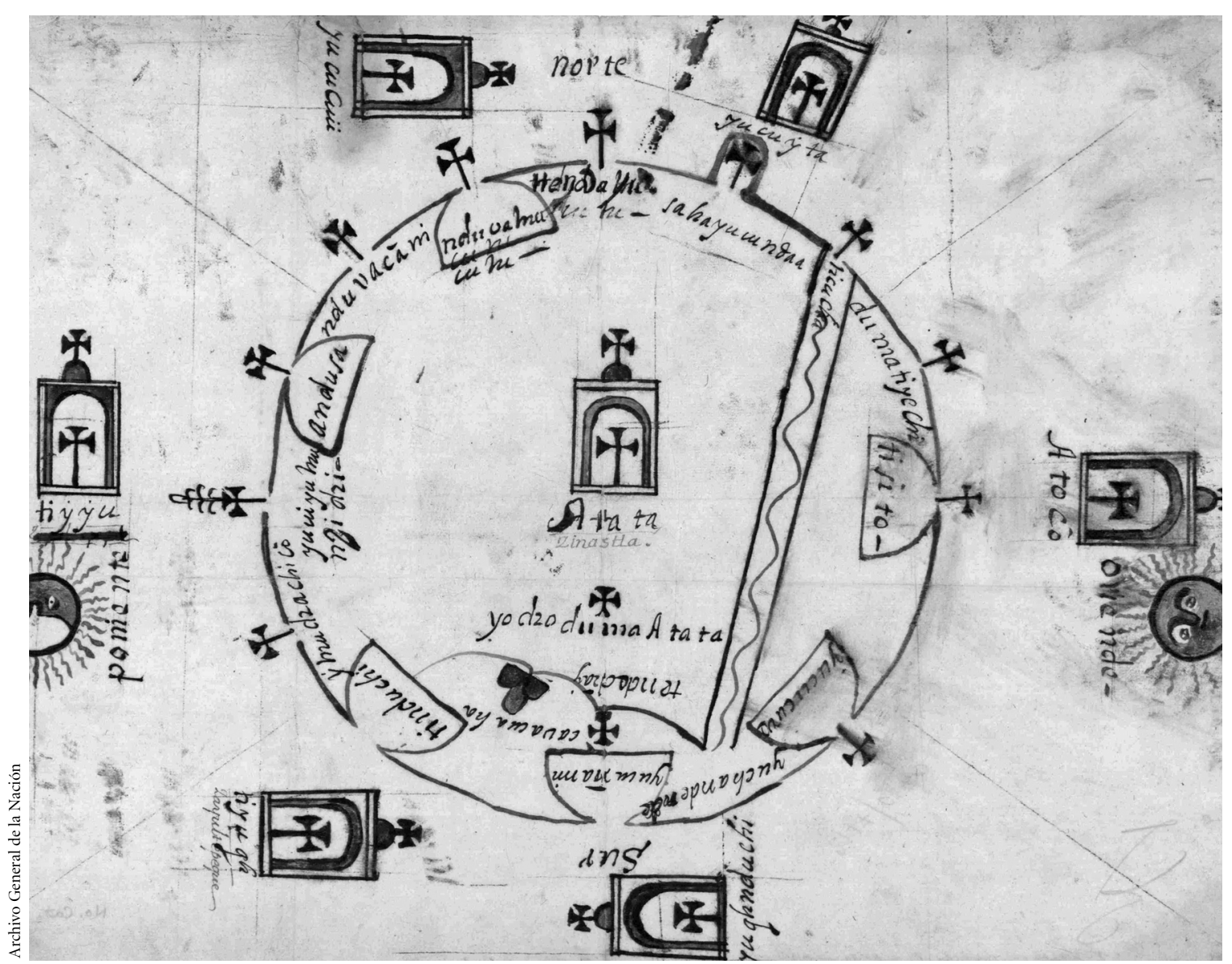

San Andrés Sinaxtla, Oaxaca. Mapoteca, AGN.

subalternos en la historia del México prehispánico, colonial y decimonónico, explorando e interrogando las fuentes con imaginación. Los artículos son comentados por un abogado, quien retoma la problemática de los archivos históricos desde la perspectiva de la Ley Federal de Transparencia y Acceso a la Información Pública, bajo una visión de carácter técnico-jurídico y reflexionando sobre el impacto que la ley tiene o debería tener.

$\mathrm{Al}$ recorrer la historia desde el momento en que cada archivo fue creado, organizado y puesto a la disposición del público para su estudio, se transparenta el nivel de la conciencia histórica de los custodios de los archivos. Por medio de la descripción de las condiciones materiales en las que los archivos han subsistido desde que fueron crea- dos, la presentación de los instrumentos de búsqueda de sus contenidos, el aporte para el conocimiento de la historia que el archivo proporciona, los estudios en conjunto problematizan la relación de cada uno de los acervos con la nueva ley. En las exposiciones se perfila la opinión de que la ley no alcanza a subsanar las lagunas inherentes a la trayectoria histórica de los archivos. Los artículos no son concluyentes sino que invitan a la reflexión sobre las políticas, las normas, la administración y la visión creativa de los custodios de los archivos y de la sociedad en general para que la memoria histórica de México no sufra menoscabos irreparables, sea organizada para preservarla y puesta al servicio del público para su estudio y permanente reinterpretación. 